\title{
Medir, controlar y proyectar: la cartografía urbana de las Luces como nuevo campo del saber
}

\author{
Measure, Control and Project: The Urban Mapping \\ of the Enlightenments as a New Field of Knowledge \\ Juan Calatrava
Ana del Cid Mendoza \\ Universidad de Granada
}

CESXVIII, núm. 30 (2020), págs. 95-123

DOI: https://doi.org/10.17811/cesxviii.30.2020.95-123

ISSN: 1131-9879

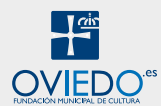




\title{
RESUMEN
}

A mediados del siglo XVIII la confluencia entre el cientifismo ilustrado y las exigencias modernizadoras de los Estados dio lugar a un giro radical en la representación cartográfica de territorios y ciudades. Una intelligentsia compuesta de científicos, ingenieros, geógrafos, geómetras, etc. produjo en menos de cincuenta años muchos ejemplos de este novedoso modo de mirar el mundo que encarnaba a la perfección el Sapere aude! de Kant. Este artículo trata de esbozar, mediante el análisis de algunos casos paradigmáticos, la naturaleza de los planos urbanos de las Luces como producto de la exigencia de un conocimiento cierto de la fisonomía del entorno y como expresión cartográfica de las ideas de progreso, felicidad pública y riqueza de la nación, así como de la cara utópica del pensamiento ilustrado.

Palabras clave

Cartografía, planos urbanos, Ilustración, ciudades del siglo XVIII, historia urbana

\begin{abstract}
In the mid-eighteenth century the confluence of Enlightenment scientism and modernizing demands of the States gave rise to a radical turn in the cartographic representation of territories and cities. An intelligentsia composed by scientists, engineers, geographers, surveyors, etc. produced in less than fifty years many examples of this new way of looking at the world that embodied perfectly the Kantian Sapere Aude! This article attempts to outline, through the analysis of some paradigmatic cases, the nature of Enlightenment urban maps as a product of the requirement of a certain knowledge of the environment physiognomy, and as the cartographic expression of the ideas of progress, public happiness, and wealth of the nation, as well as the utopic face of Enlightenment thinking.
\end{abstract}

\section{Key Words}

Cartography, urban maps, Enlightenment, eighteenth-century cities, urban history.

Recibido: 16 de enero de 2020. Aceptado: 11 de marzo de 2020. 


\section{Introducción}

Como ocurrió en todos los demás ámbitos de la cultura y de la técnica, la gran cesura que representa el siglo XVIII introdujo cambios y novedades muy significativas en el campo de la representación gráfica del entorno del hombre. Si es cierto que el siglo de las Luces no inventó la cartografía científica (baste con recordar la brillante historia de la cosmografía renacentista o de los cartógrafos holandeses de los siglos XVI y XVII ${ }^{1}$ ), no lo es menos que, desde la matriz del pensamiento ilustrado, se registraron importantes innovaciones tanto en el modo y en las técnicas de plasmar sobre el papel la imagen del territorio como, particularmente, en el concepto mismo de la representación cartográfica, sus objetivos, sus modos y sus usos.

La confluencia entre el pensamiento ilustrado, los avances geográficos y científicos ${ }^{2}$ y las exigencias de nuevas formas de control por parte de los aparatos de Estado fue el caldo de cultivo no solo de un aumento numérico exponencial de los documentos cartográficos, sino también de una creciente variedad y especialización de estos, acorde con los nuevos y múltiples usos que se esperaba de ellos ${ }^{3}$. Si el cientifismo exigía ahora de los mapas territoriales y de los planos urbanos la mayor exactitud, desde los parámetros de la idea de progreso la cartografía se convertía también en incitación al desvelamiento de lo desconocido y en promesa de futuro, mutando incluso en herramienta para diseñar la forma que se deseaba para ese futuro, como si darle representación cartográfica conjurara ya de manera inevitable el destino de un territorio o una ciudad. La cartografía ilustrada nos confirma así, una vez más, hasta qué punto los mapas y planos son, ante todo, constructos histórico-culturales de primer nivel de interés ${ }^{4}$. Como re-

\footnotetext{
1 Sin poder adentrarnos ahora en la amplísima bibliografía al respecto, el mejor y más útil compendio es David Woodward (ed.), Cartography in the European Renaissance, vol. 3 de History of Cartography, Chicago, The University of Chicago Press, 2007.

2 Numa Broc, La géographie des philosophes. Géographes et voyageurs francais au XVIIİme siècle, París, Ophrys, 1974.

3 Matthew H. Edney y Mary Sponberg Pedley (eds.), Cartography in European Enlightenment, vol. 4 de History of Cartography, Chicago / Londres, The University of Chicago Press, 2019.

4 Ana del Cid Mendoza y Juan Calatrava, «Por sus mapas los conoceréis. La cartografía como documento de cultura», en Fuera de plano, Valencia, General de Ediciones de Arquitectura, en prensa.
} 
sumió certeramente John Rennie Short, en una afirmación que puede aplicarse de manera muy especial a la cartografía del siglo XVIII:

Los mapas no son ni espejos de la naturaleza ni transmisores neutrales de verdades universales. Son narrativas con un objetivo, historias con una agenda. Contienen silencios en la misma medida que articulaciones, secretos en la misma medida que conocimiento, mentiras en la misma medida que verdades. Son predeterminados, parciales y selectivos ${ }^{5}$.

La aspiración ilustrada al conocimiento universal encuentra en la creciente precisión de las representaciones cartográficas una de sus mejores metáforas. Las Luces contemplan ahora los vacíos de los mapas como un mero obstáculo al progreso del saber, un obstáculo que tarde o temprano será eliminado por los avances imparables de una ciencia para la cual no existen ya territorios vedados. Pero, mientras tanto, el Sapere aude! de Kant se verá continuamente matizado por la advertencia newtoniana del hypotheses non fingo para producir una imagen del entorno del hombre de la que queda ya completamente proscrita la fantasía de los cartógrafos de épocas anteriores. Es algo que expresó, con su habitual ironía, Jonathan Swift:
So geographers, in Africa maps,
with savage-pictures fill their gaps,
and other inhabitable downs
place elephants for want of towns ${ }^{6}$.

Pero, dos décadas más tarde, fue el turno de Jean-Jacques Rousseau, quien se refirió explícitamente a la cartografía urbana. En un texto escrito seguramente hacia finales de la década de 1750 y publicado tras su muerte, el ginebrino simboliza en un plano de la ciudad uno de los múltiples episodios de su largo enfrentamiento filosófico con París?

5 John Rennie Short, The World through Maps: A History of Cartography, Toronto, Firefly Books, 2003, pág. 24 .

6 «Geógrafos que en mapas africanos / con cuadros de salvajes llenan vanos, / y meten en desiertas soledades / elefantes a falta de ciudades». En Jonathan Swift, On Poetry: A Rhapsode, Dublín, J. Huggonson, 1733; extraído de Karl SchlöGEL, En el espacio leemos el tiempo, trad. de José Luis Arántegui, Madrid, Siruela, 2007, pág. 165.

7 Juan Calatrava, «City and Architecture in Rousseau's Thought», en Leonor Ferrao y Luis Manuel A. V. Bernardo (eds.), Views on Eigheteenth Century Culture. Design, Books and Ideas, Newcastle upon Tyne, Cambridge Scholars Publishing, 2015, págs. 20-43. 
No me gusta siquiera preguntar la calle a la que tengo que ir, porque dependo en ello de quien va a responderme. Prefiero errar dos horas buscando inútilmente; llevo en mi bolsillo un mapa de París con cuya ayuda y la de unos anteojos termino por encontrarme, llego lleno de barro, molido, a veces demasiado tarde, pero consolado de no deber nada más que a mí mismo ${ }^{\text {. }}$

Estas dos citas pueden resumir cómo se ha producido la traslación al ámbito urbano de los esfuerzos de las cartografías territoriales y nacionales. Un tránsito que se produce con no pocos problemas relacionados, sobre todo, con la especificidad de los planos urbanos y sus nuevos usos. El reconocimiento teórico de la existencia autónoma de la cartografía urbana se hará esperar: el mapa por excelencia es el mapa territorial, y hay que recordar que la obra-faro de la Luces, la Encyclopédie de Diderot y D’Alembert, no incluyó la más mínima referencia a los planos de ciudades en la voz Carte $^{9}$.

Estas carencias en cuanto al estatus teórico no obstan, sin embargo, para reconocer el hecho de que, pese a precedentes de la anterior centuria, el XVIII supuso el verdadero inicio y, en sus décadas finales, la generalización, de los planos geométricos ${ }^{10}$ realizados con levantamientos trigonométricos, con escala idéntica en todo su campo y, lo que es más importante, con objetivos ya no solo figurativos, sino operativos.

Fue sobre todo a partir de 1730-40 cuando se produjo un nuevo giro en la imagen gráfica de la ciudad, especialmente en Francia e Inglaterra, que rompieron el predominio de una Holanda ya anclada a planteamientos más comerciales que científicos, pero también en Italia y, aunque en menor medida y con retraso, en España. Los planos de París entre Turgot (1739) y Verniquet (1791), la Nuova pianta di Roma de Giambattista Nolli (1748), los planos urbanos de Inglaterra y Escocia de J. Rocque (1734-1762) o los planos de Madrid de Tomás López (1785) y de Antonio Espinosa de los Monteros (1769) son solo algunos hitos de un proceso en el que jugaron un papel fundamental los intercambios tanto con la ciencia como con la pintura (sobre todo con los vedutistas italianos).

Lo importante es, pues, que los mapas y los planos urbanos del siglo XVIII comenzaron a ser no solo una representación — cada vez más fidedigna, aunque no por ello objetiva — de la realidad, sino también la expresión de una propuesta

\footnotetext{
8 Jean-Jacques RoussEAu, «Mi retrato», Las ensoñaciones del paseante solitario, trad. de Mauro Armiño, Madrid, Alianza Editorial, 1979, págs. 168-176; pág. 174.

9 Denis Diderot y Jean le Rond D’Alembert, Encyclopédie ou Dictionnaire raisonné des sciences, des arts et des métiers, vol. 2, París, Briasson-David-Le Breton-Durand, 1752, págs. 706-709.

10 Nicolas Verdier, «Les cartes du XVIIIe siècle: de l'image à la représentation géometrale», en Laurent Costa y Sandrine Robert (dirs.), Guide de lecture des cartes anciennes, París, Errance, 2009, págs. 6-9.
} 
de futuro, de un desideratum que se visualizaba antes de existir, precisamente, para hacer posible su existencia. En este sentido, hay que señalar cómo algunos mapas y planos de las Luces añadieron a su objetivo primordial de retrato fidedigno del presente para mejor medir y controlar una dimensión temporal de futuro. A continuación trataremos de representar esta compleja problemática a través de algunos ejemplos elegidos como casos de estudio especialmente significativos.

\section{Cuatro hitos del París de las Luces}

La brillante historia de la cartografía francesa durante el siglo XVIII, simbolizada por la gran empresa del mapa nacional de los Cassini ${ }^{11}$, tiene su directo correlato urbano en la evolución de la cartografía de París a lo largo de la centuria $^{12}$. La ciudad cuna de las Luces vio, en efecto, cómo, en un periodo de seis décadas, los avatares de su imagen cartográfica reflejaban puntualmente tanto el anhelo generalizado de embellissement de la ciudad como las nuevas aspiraciones de los philosophes y de los técnicos, ingenieros y gestores de la urbe. En este sentido, París fue el escenario principal del debate sobre qué era un plano urbano y qué cabía esperar de él, tanto como retrato fiel de la situación real cuanto como herramienta para las transformaciones de esa misma realidad. Resumiremos esta evolución en cuatro hitos cartográficos reveladores.

El primer jalón es el Plan Turgot $t^{13}$, llamado así por partir su iniciativa de Michel-Étienne Turgot, preboste de los comerciantes (y padre del mucho más famoso Anne-Robert-Jacques Turgot). El plano, a escala aproximada de 1:400, fue elaborado por Louis Bretez, académico y autor de La Perspective pratique de l'architecture (1706), y grabado por Antoine Coquart y Claude Lucas en 20 planchas de cobre (más otra con un cuadro global) que componen un gran conjunto de $2490 \times 3260 \mathrm{~mm}$.

11 Monique Pelletier, Les cartes des Cassini, la science au service de l'État et de ses régions, París, CTHS, 2002. Véase también, de entre una numerosa bibliografía, Nicolas VERDIER, La carte avant les cartographes. L'avènement du régime cartographique en France au XVIIIe siècle, París, Éditions de la Sorbonne, 2015.

12 Jean Des Cars y Pierre Pinon, Le dessus des cartes. Un atlas parisien, París, Picard, 1999; Jean Boutier, Marine Sibille y Jean-Yves Sarazin, Les plans de Paris des origines (1493) à la fin du XviIIe siècle, París, Bibliothèque Nationale de France, 2002; Pierre Pinon, Les Plans de Paris. Histoire d'une capitale, París, Bibliothèque Nationale de France / Le Passage, 2014.

13 Bernard Rouleau, Le plan de Paris de Louis Bretez dit Plan de Turgot, Nördlingen, Verlag Dr. Alfons Uhl, 1989; Stéphane BLOND, «Le plan Turgot», Histoire par l'image [website], entrada de diciembre de 2016, http://www.histoire-image.org/fr/etudes/plan-turgot, consultado el 1 de octubre de 2019; Alfred FIERRo y JeanYves Sarazin, Le Paris des Lumières d'après le plan de Turgot (1734-1739), París, RMN, 2005. 


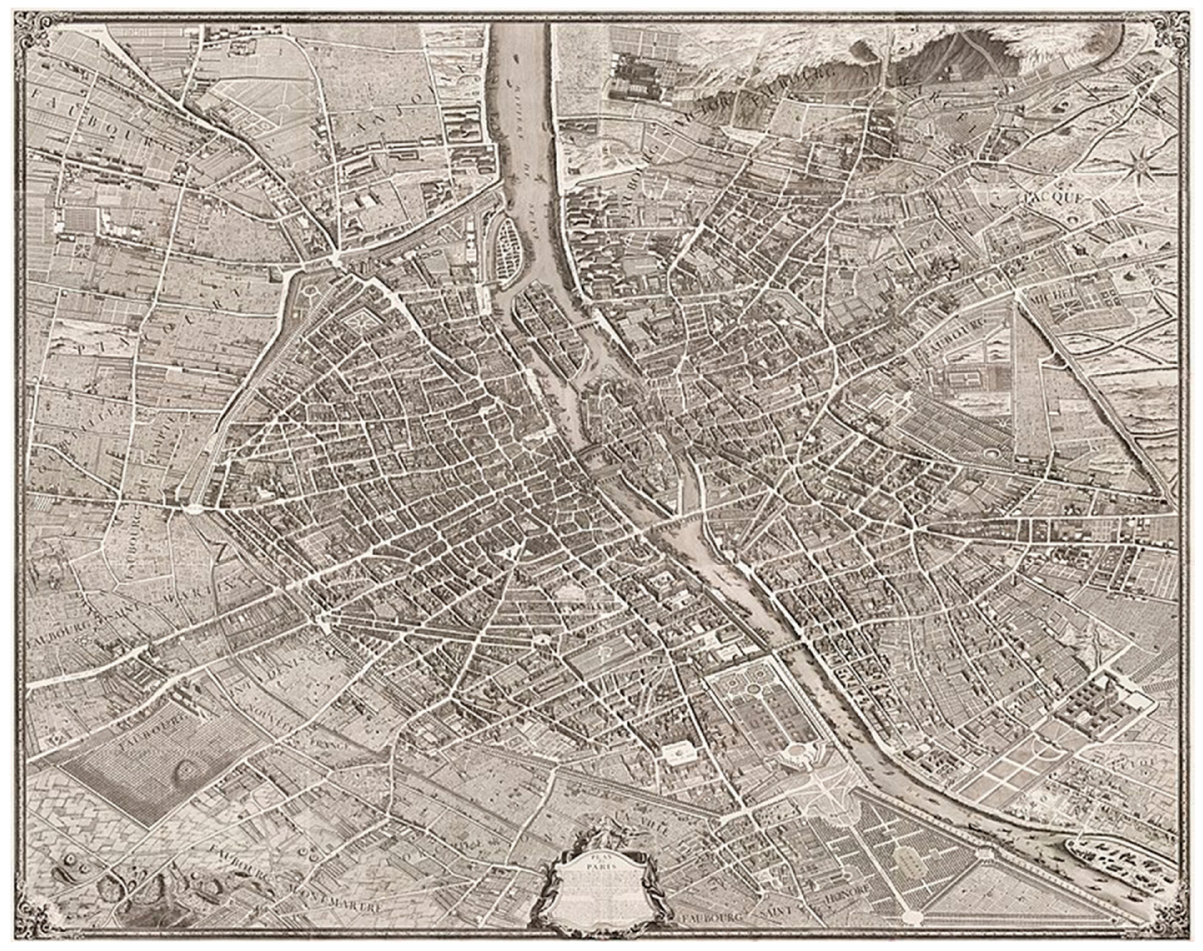

Figura 1. Plano de París de Louis Bretez o Plan Turgot (1739)

Lo que más nos interesa ahora de este plano es su aparente anacronismo, por tratarse de una vista en perspectiva caballera, atenta sobre todo a la representación de los edificios de la ciudad ${ }^{14}$, y no de un plano geométrico. En un momento en que París ya había conocido alguna tentativa de cartografía no pictórica, el plano Turgot distorsionaba la anchura de las calles e incluso argumentaba, en su texto de acompañamiento, la necesidad de tales licencias ${ }^{15}$. También iba contra corriente la orientación SE, elegida sin duda para tomar la línea del Sena como eje estructurador de la composición. El plan Turgot-

14 El de Turgot no es, sin embargo, un caso único. A mediados del siglo XVIII no faltan anacronismos de este tipo, como ha estudiado, por ejemplo, para el caso de Parma, Franca Miani Uluhogian, «Dall'immagine simbolo all'immagine rappresentazione: l'iconografia di Parma tra vedutismo e cartografia dal XVI al XVIII secolo», en Daniela Romagnoli (ed.), Storia e storie della città, Parma, Pratiche Editrice, 1989, págs. 105-122.

15 «Nos hemos propuesto, al grabar este Plano de la Ciudad de París, hacer ver de un solo golpe todos los edificios y todas las calles que encierra, lo cual no podía llevarse a cabo sin algunas licencias que las reglas austeras de la Geometría y de la Perspectiva condenan; pero sin estas licencias se habría perdido una parte de los objetos más interesantes, que quedarían ocultos por otros o enteramente desfigurados» (traducción del francés, Juan Calatrava). 
Bretez era, así, un producto claramente híbrido. Por un lado, representaba el culmen de las funciones celebrativas de las vistas urbanas, y, en este sentido, no era eficaz como instrumento para vislumbrar el futuro de la ciudad: se limitaba a congelar la imagen del París resultante del Grand Siècle. Pero, por otro lado, el rigor con el que se utilizaba la perspectiva caballera lo convertía, pese a sus inevitables deformaciones, en un retrato minucioso de las calles y edificios de París.

En 1765 aparecía nuestro segundo ejemplo, el plano de París trazado por el arquitecto Pierre Patte ${ }^{16}$. Se trata de una representación verdaderamente sui generis. Su origen se encuentra en los dos concursos convocados en 1748 y 1753 para la sistematización en París de una place royale en honor a Luis Xv. En el primero de ellos se pidió a los participantes que propusieran no solo el diseño de la plaza, sino también su emplazamiento en la ciudad (que resultaría ser el de la actual Place de la Concorde, para cuya ordenación se convocó el segundo concurso).

Los proyectos presentados a la convocatoria de 1748 fueron compilados por Patte en 1765 en su Monumens érigés en France à la gloire de Louis $\mathrm{XV}^{17}$, con un plano en el que figuran todas las propuestas insertadas en su ubicación. El resultado fue, por tanto, una imagen de un París soñado, cuyo callejero apiñado aparece ahora por todas partes abierto por plazas y surcado por monumentos. Se trata de una ciudad marcada por la doble exigencia de claridad geométrica y belleza monumental. Y así, el plano de Pierre Patte se inserta en el quebrado recorrido de la cartografía parisina ilustrada como el punto en el que se produce el encuentro entre realidad y utopía, entre representación de la ciudad existente y premonición (o deseo) de un futuro esplendoroso gracias al triunfo de los ideales del progreso y la razón.

Pero, sin duda, el hito cartográfico de mayor trascendencia del París de las Luces es el Plan de la ville de Paris avec sa nouvelle enceinte, levé géométriquement sur la méridienne de l'Observatoire par le citoyen Verniquet, realizado

16 Autor de importantes publicaciones como las Mémoires sur les objets les plus importants de l'architecture (1769) o el Essai sur l'architecture théatrâle (1782), Pierre Patte también pasó a la historia interna de las Lumières al acusar, en 1759, de plagio a Diderot y a los editores de la Encyclopedie en relación a algunas de las Planches de la gran obra colectiva. Véase Antoine Picon, Architectes et ingénieurs au siècle des Lumières, Marsella, Parenthèses, 1988. Juan Calatrava, La teoría de la arquitectura y de las bellas artes en la Encyclopédie de Diderot y D'Alembert, Granada, Diputación Provincial, 1992.

17 Pierre Patte, Monumens érigés en France à la gloire de Louis XIV, París, Chez l'auteur, 1765. Accesible online: https://gallica.bnf.fr/ark:/12148/bpt6k1041169x. Véase, además, Yvonne RickERT, «Une célébration du roi? Pierre Patte et ses Monumens érigés en France à la gloire de Louis XV», Les Cahiers de Framespa [online], 11 (2012), http://journals.openedition.org/framespa/1842, consultado el 1 de octubre de 2019. 


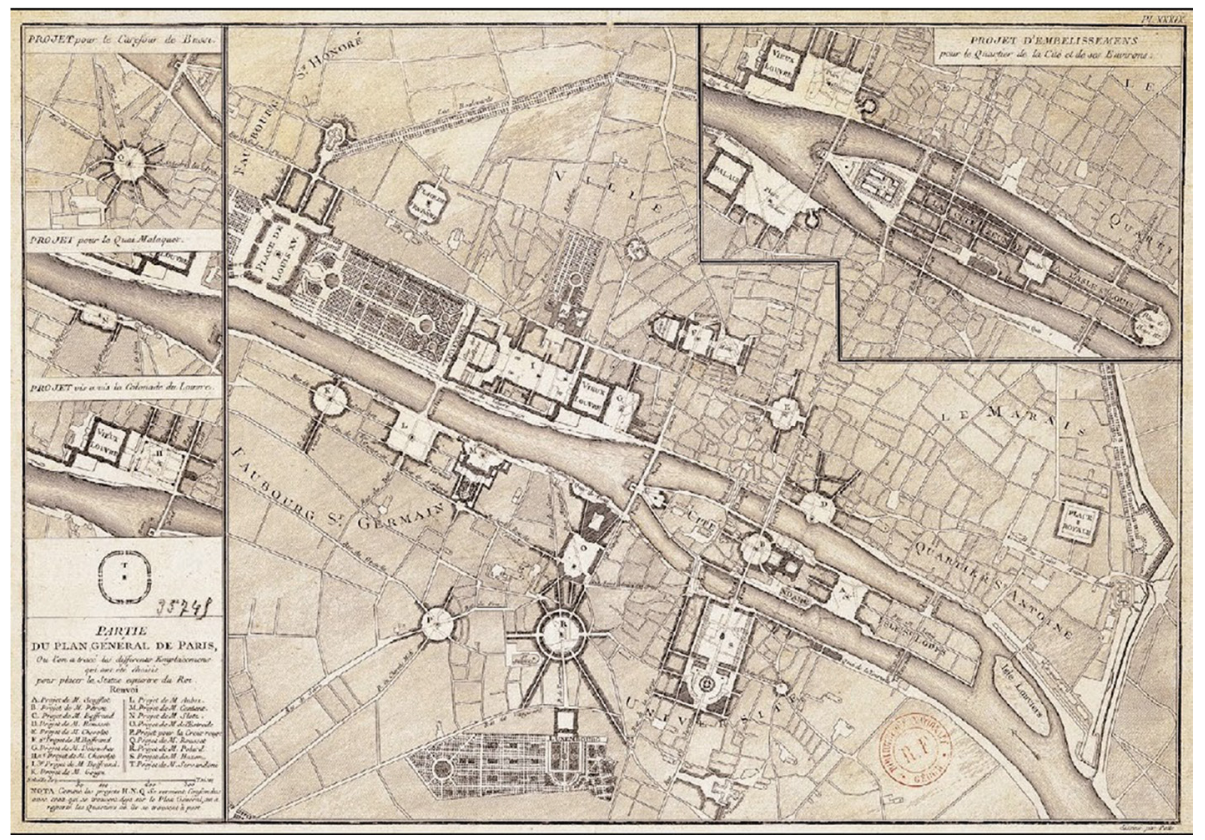

Figura 2. Plano incluido en Monumens érigés en France à la gloire de Louis XV (1765)

entre 1785 y 1791 por el arquitecto Edmé Verniquet ${ }^{18}$. Descendiente de una familia borgoñona de arpenteurs, Verniquet desarrolló una amplia obra como arquitecto en Borgoña y París. En 1774 compró uno de los cuatro puestos de dirección de la voirie de París, desde el cual, al contrario que otros ocupantes de cargos similares que los consideraban meramente como sinecuras, emprendió una continuada labor de conocimiento exhaustivo y propuestas de reforma del viario de la urbe.

La ocasión para pasar a una empresa científica de mayor envergadura se la dio, en 1783, el decreto real que impuso una anchura mínima a las calles de la ciudad y acarreó la exigencia de un levantamiento general del viario parisino. Esta necesidad fue la base del encargo de 1785 de levantar un plano general de París y de sus alrededores.

El de Verniquet fue el primer plano de París basado en un levantamiento sistemático fundamentado en la trigonometría y realizado sobre el terreno por un equipo de más de sesenta ingenieros, topógrafos y dibujantes, cuyo trabajo colectivo dio como resultado no solo la imagen cartográfica, sino también una

\footnotetext{
18 Jean Pronteau, Edme Verniquet, París, Comission des travaux historiques de la Ville de Paris, 1986.
} 


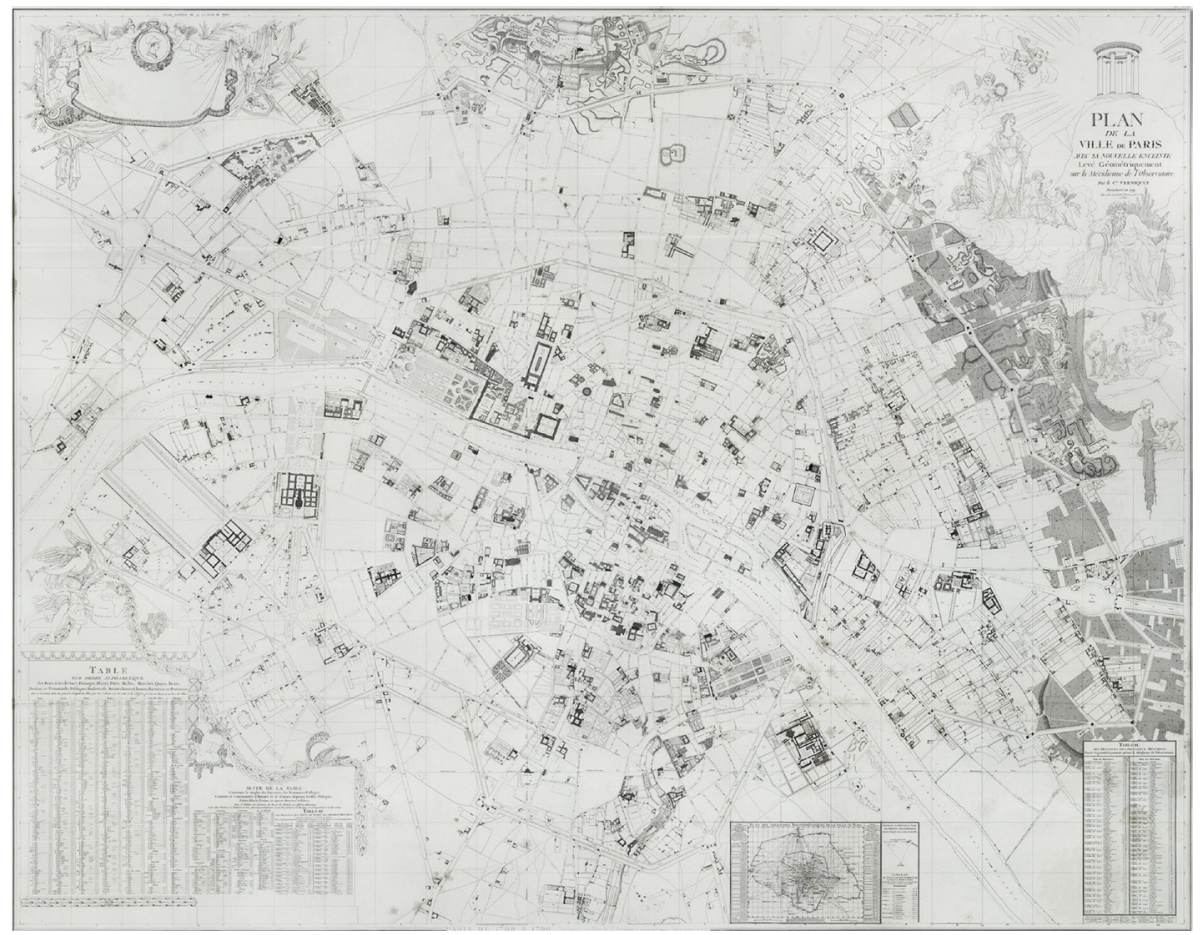

Figura 3. Plan de la ville de Paris avec sa nouvelle enceinte, levé géométriquement sur la méridienne de l'Observatoire par le citoyen Verniquet o plano de Verniquet (1791)

masa de información diversa de una envergadura como no había conocido antes la ciudad. Los trabajos de trigonometría se iniciaron a partir del meridiano y su perpendicular en el Observatorio de París (cuyo director, el célebre Jerôme Lalande, definió al plano como la obra más perfecta jamás ejecutada en su género). La representación se culminó en 1791: un documento de grandes dimensiones, compuesto por 9 hojas montadas en matriz de $3 \times 3$. En 1793 se inició el proceso de grabado en cobre para su edición y en 1795, finalmente, se publicó como atlas de 72 hojas.

Tanto su minucioso y científico proceso de elaboración como la rigurosa exactitud de la representación resultante hacen del plano de Verniquet, independientemente de su interés para la historia de París, uno de los monumentos cartográficos que mejor ejemplifican los ideales de las Luces y los cambios radicales producidos en la cartografía urbana en tan solo unas pocas décadas.

Una secuela inesperada del plano de Verniquet fue, por último, su utilización como base para plasmar los proyectos de reforma de París durante el pe- 


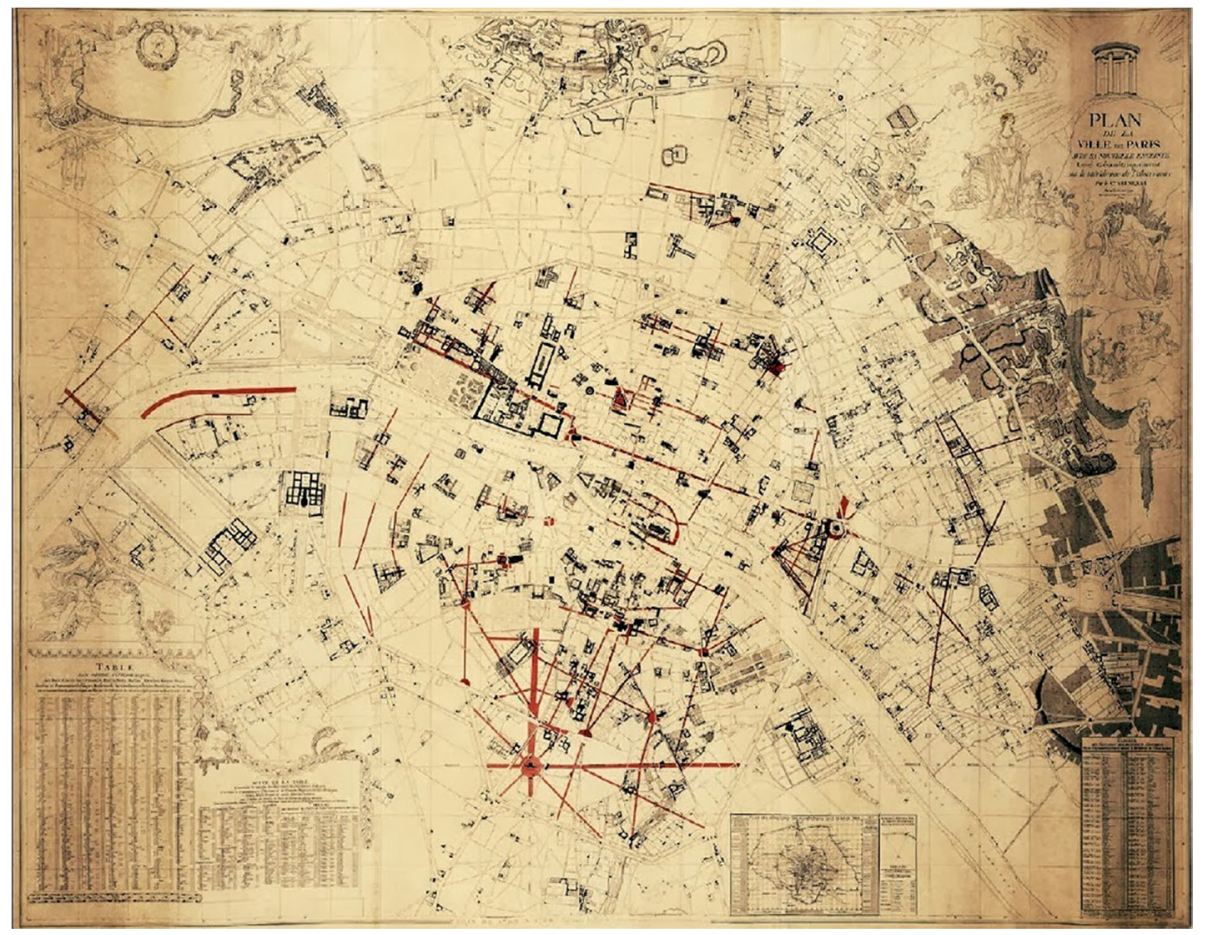

Figura 4. Plan des Artistes sobre el plano de Verniquet (1793)

riodo álgido de la Revolución, la Convention nationale. La posibilidad, e incluso la exigencia, de introducir importantes reformas urbanas en la ciudad se planteó como consecuencia directa de los decretos de abril de 1793 que dictaminaban la parcelación y venta de los bienes inmuebles expropiados al clero o a los emigrés. Que este gigantesco proceso de expropiaciones podía producir grandes transformaciones en la trama urbana de París y que era preciso ordenarlas de algún modo es algo que fue inmediatamente comprendido por la Convención, la cual decidió crear exprofeso una Comisión de Artistas en la que, además de renombrados arquitectos como Louis-François Petit-Radel o Charles de Wailly, se encontraba el propio Verniquet. La necesidad de un plano adecuado como soporte de los trabajos de la comisión llevó a Verniquet a grabar la hoja grande de su plano.

Del nuevo París que quedó trazado en el llamado Plan des Artistes nada se realizó, a causa de la propia evolución de los acontecimientos históricos, pero algunas de sus previsiones encontraron eco sesenta años más tarde en los grands travaux del barón Haussmann. 
La densa problemática de la cartografía parisina no se agota con estos ejemplos, aunque sean sin duda de los más significativos — habría que recordar, por ejemplo, la importancia del plano/plan de Charles de Wailly de 1789, con una propuesta global de reestructuración de París-, pero los cuatro casos elegidos representan tanto la coexistencia histórica de modos diversos de mirar la realidad como, sobre todo, el creciente protagonismo de la dimensión de futuro, incorporada como mera aspiración en el caso de Pierre Patte, pero ya como programa concreto de reformas en el Plan des Artistes.

\section{El prototipo romano: la planta de Nolli}

La Nuova pianta di Roma, publicada en 1748 y elaborada por el topógrafo y arquitecto lombardo Giovanni Battista Nolli ${ }^{19}$, es otro de los grandes hitos de la cartografía urbana de las Luces. Obra absolutamente vanguardista, en palabras de Marcello Fagiolo, «constituye un monumento de la ciencia ilustrada» ${ }^{20}$. Su precisión científica y su calidad estética son tales que no solo se implantó internacionalmente durante décadas como modelo de referencia ${ }^{21}$, sino que, hasta la segunda mitad del siglo XX, sirvió como base para numerosos levantamientos planimétricos de Roma.

Nolli realizó, como indica el propio título de la obra, una verdadera representación en planta de la ciudad. A diferencia del parisino Plan Turgot (1739), prácticamente contemporáneo, la Nuova pianta no es una vista en perspectiva en la que las dimensiones reales resulten deformadas y difícilmente mensurables. De hecho, podríamos considerar al plano nolliano como uno de los más antiguos antecesores de lo que hoy conocemos como plano de llenos y vacíos,

19 Mario Bevilacqua, Roma nel secolo dei Lumi. Architettura, erudizione, scienza nella pianta di G. B. Nolli «celebre geometra», Nápoles, Electa Napoli, 1998; Mario Bevilacqua, «Le piante di Roma da Bufalini a Nolli: un modello europeo», en Mario Bevilacqua y Marcello Fagiolo (a cura di), Piante di Roma dal Rinascimento ai Catasti, Roma, Artemide, 2012, págs. 54-87; Allan Ceen, Erik Steiner y James Tice, The Nolli Map Website, Universidad de Oregón, 2005-2020, http://nolli.uoregon.edu/default.asp, consultado el 1 de octubre de 2019; Clemente Faccioli, «Gio. Battista Nolli (1701-1756) e la sua gran Pianta di Roma del 1748», Studi Romani, XIV (1966), págs. 415-443; Carlo M. Travaglini y Keti Lelo (eds.), Roma nel Settecento. Immagini e realtà di una capitale attraverso la pianta di G.B. Nolli, Roma, CROMA, 2013.

20 Bevilacqua, Roma nel secolo dei Lumi, pág. 9.

21 El ingeniero militar José de Hermosilla (responsable en 1766 del primer levantamiento planimétrico de la Alhambra) y el grabador Antonio Espinosa de los Monteros (principal artífice del plano topográfico de Madrid de 1769) estudiaron de primera mano, durante sus años como pensionados en Roma, la entonces recién publicada pianta di Nolli. Véase Delfín Rodríguez Ruiz, «José de Hermosilla. Arquitecto», en Miguel Ángel Melón Jiménez y Delfín Rodríguez Ruiz (coords.), José de Hermosilla y Sandoval, Badajoz, Diputación provincial de Badajoz, págs. 17-45. 
cuyas manzanas densamente sombreadas permiten diferenciar a simple vista espacio abierto y construcción. La obra hace gala de una asombrosa precisión del dibujo, conseguida probablemente con levantamientos topográficos sectoriales a gran escala, entre 1:100 y 1:300 —dependiendo de la complejidad del sector-, trasladados posteriormente con exactitud y detalle al plano general, el cual presenta una escala aproximada de 1:2910 22 .

A propósito de esta vocación científica de la Nuova pianta, y teniendo presente que fue una empresa promovida por miembros de la élite intelectual del clero —el canónigo Antonio Baldani y el abate Diego de Revillas—, resulta inevitable confrontarla con ciertos precedentes contrarreformistas enfocados a asentar la imagen de Roma como capital de la religiosidad tridentina: por ejemplo, Le sette chiese di Roma (1575), de Antonio Lafréry, y Le sette chiese privilegiate di Roma (1589), incorporado en el libro homónimo de Nicolaus van Aelst (dos vistas urbanas alucinadas en las que la urbe se reduce a un terreno yermo atravesado por el Tíber y colonizado tan solo por sus siete grandes basílicas — dibujadas con todo detalle_- unas murallas y fieles en peregrinación) o la representación del plan urbanístico sixtino incluida por Giovanni Francesco Bordino en su biografía De rebus praeclaris gestis a Sisto V (1588), de un reduccionismo que remplaza cada basílica por la imagen sagrada de su advocación ${ }^{23}$. Con respecto a todo este cúmulo de visiones sacralizadas, el plano de Nolli representaba una inversión radical de paradigma.

Otro de los cambios instaurados por el plano de Nolli fue la rotación del dibujo para ubicar el norte (magnético), en vez del acostumbrado este, hacia arriba. La indicación del norte astronómico se realiza mediante una rosa de los vientos ubicada junto a la planta de San Giovanni in Laterano. Nolli consiguió así asentar la imagen reorientada de Roma. Es de destacar, igualmente, la restitución gráfica, apoyada en estudios científico-arqueológicos, de las murallas y los monumentos de la Antigüedad desaparecidos parcialmente. Además, Nolli realizó el extraordinario esfuerzo de representar la planta baja de los edificios más significativos (públicos o privados, religiosos o no) —destacándolos con una trama más densa- así como de distinguir los claustros, atrios y patios abiertos en todas las edificaciones salvo las menores.

Igualmente importante es la exhaustiva representación de columnas, columnatas, cruces, escaleras, fuentes, obeliscos, etc., y del trazado de los jardines, así como del arbolado y las parcelas agrícolas, estas últimas con tramas que

22 Bevilacqua, Roma nel secolo dei Lumi, págs. 9-13.

23 Sobre la cartografía histórica romana sigue siendo imprescindible la compilación de Aimé-Pierre Frutaz, Le piante di Roma, Roma, Istituto di Studi Romani, 1962. Véase, también: Italo Insolera, Roma, Roma / Bari, Laterza, 1980; Bevilacqua y Fagiolo (eds.), Piante di Roma. Dal Rinascimento ai Catasti. 


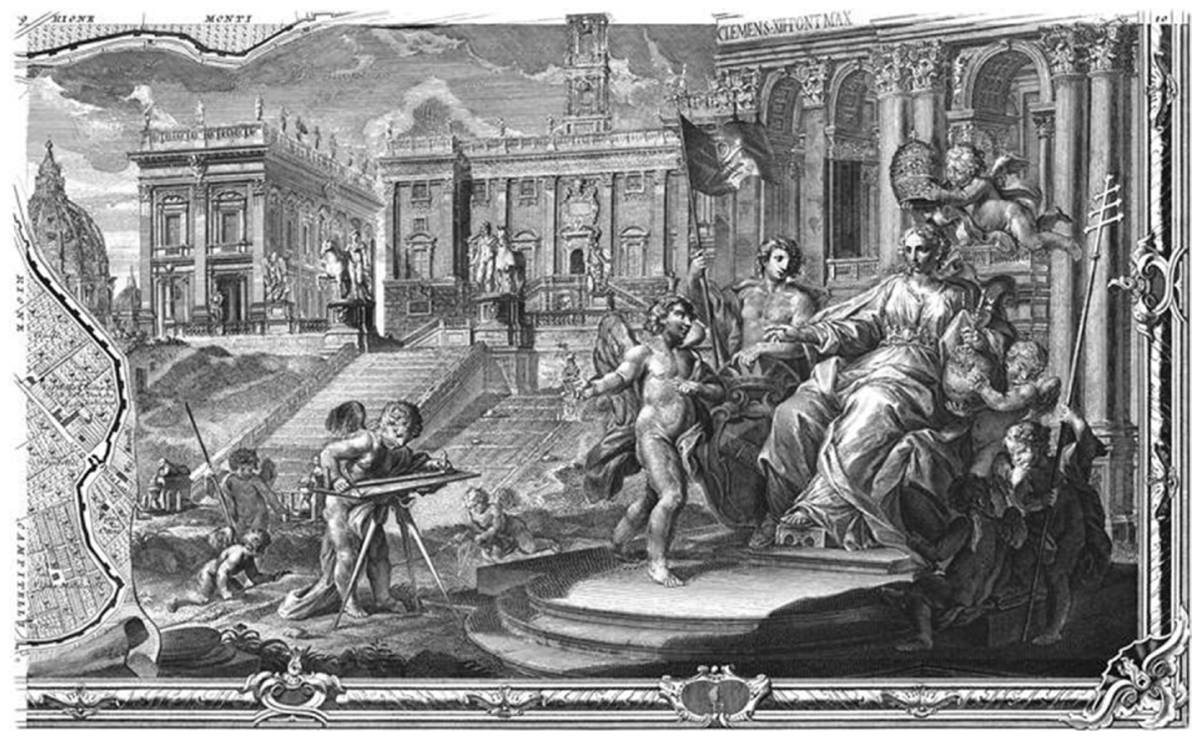

Figura 5. Alegoría de la Roma moderna en la Nuova pianta di Roma (1748)

figuran los tipos esenciales de cultivo. Y debajo de todo ello (cuando la trama urbana no lo impide), aflora un sombreado a trazos que simula los principales desniveles de la topografía.

Merece también atención el marco alegórico inferior del plano, ideado por el dibujante romano Stefano Pozzi. Dos escenas lo integran: la Roma antigua (y profana) y la Roma moderna (y sacra). La primera, a la izquierda, se presenta con yelmo y corona de laurel en mano, junto a la personificación del Tíber y con una deteriorada y casi irreconocible loba capitolina a sus pies. Detrás se alza todo un escenario arquitectónico en el que se distinguen con facilidad las ruinas de un templo, el Coliseo, tres arcos de triunfo así como dos columnas y dos obeliscos, paradójicamente, ya consagrados. A la derecha, la Roma santa, con una llave en su mano izquierda y rodeada de atributos papales (la esfera, el crismón y la triple cruz), es coronada con la tiara pontificia mientras bendice la labor que frente a ella realizan cuatro querubines con la cadena agrimensora y la plancheta topográfica — una posible metáfora del apoyo que tanto Clemente XII como Benedicto XIV dieron a la empresa nolliana—. El telón de fondo, en este caso, lo conforman el Campidoglio, como monumento cívico-cultural, la cúpula de San Pedro, algo lejana y solo parcialmente visible, y la fachada catedralicia de San Giovanni in Laterano, la gran obra arquitectónica del pontificado de Clemente XII y emblema religioso universal.

La edición original se componía de un plano de grandes dimensiones y dos reducciones con diferente temática. La planta grande o Nuova Topografia 


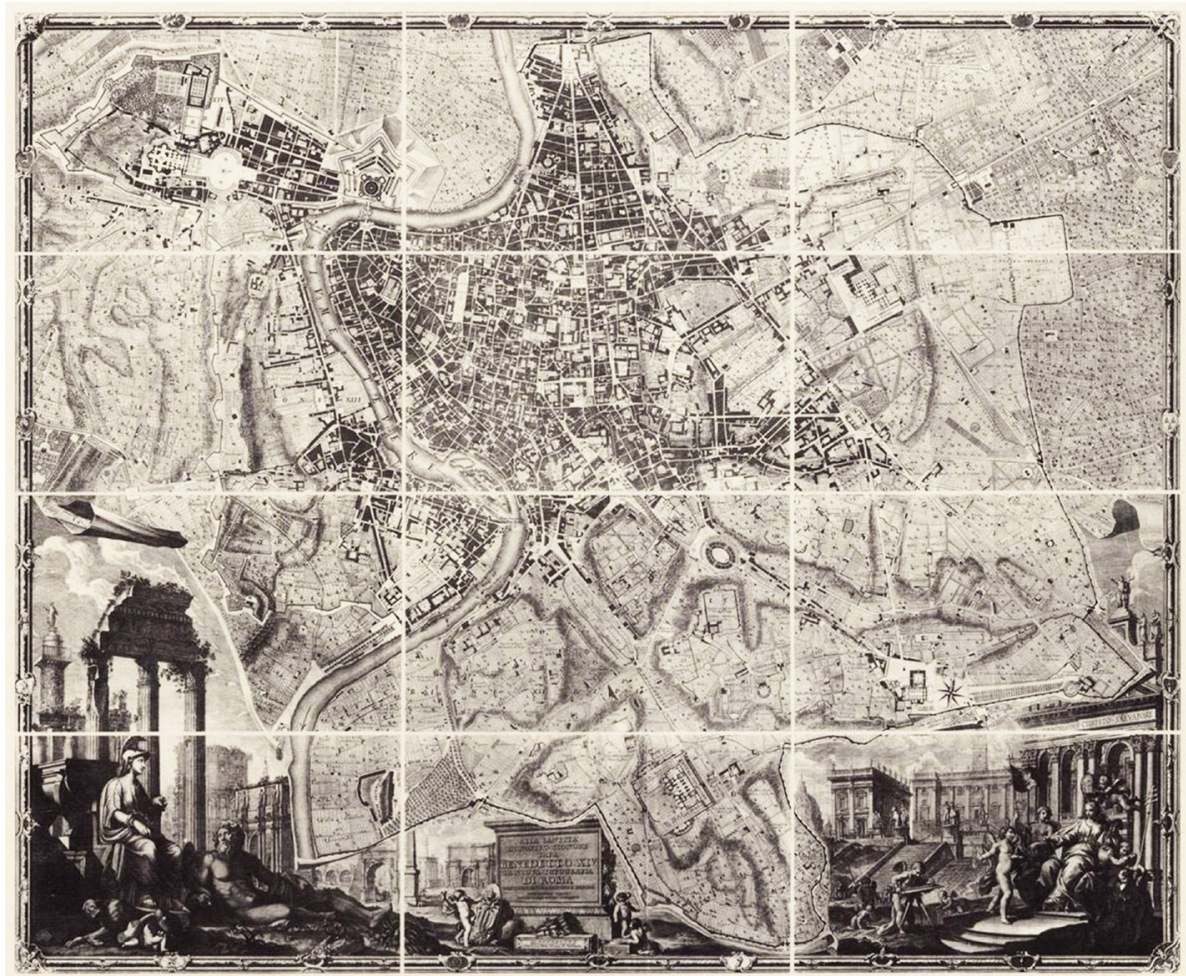

Figura 6. Nuova Topografia di Roma o pianta grande (1748)

di Roma, dedicada a la «Santità di Nostro Signore Papa Benedetto XIV» ${ }^{24}$, está formada por 12 hojas de, aproximadamente, $440 \times 695 \mathrm{~mm}$ que componen un mosaico de unos $1760 \times 2085 \mathrm{~mm}$, además de otras 4 hojas (de dimensiones similares a las primeras) que contienen las escalas gráficas (en pies antiguos romanos, pies británicos, pies de París y pies del Rin) y los índices numérico y alfabético. También en hoja aparte se recogieron el frontispicio y un «Avviso al lettore». Los responsables del grabado fueron Rocco Pozzi, su discípulo Pietro Campana y Carlo Nolli (hijo de Giambattista).

De la planta grande se hizo una reducción (La topografia di Roma di Gio. Batta Nolli dalla maggiore in questa minor tavola dal medesimo ridotta) de unos $470 \times 685 \mathrm{~mm}$ y a una escala aproximada de 1:10950. Dedicada al cardenal Alessandro Albani, fue grabada por Carlo Nolli en colaboración con el célebre

24 Así reza en forma de inscripción en lo que parece el basamento de Antonino Pío en el marco alegórico del plano, entre las escenas de las dos Romas. 


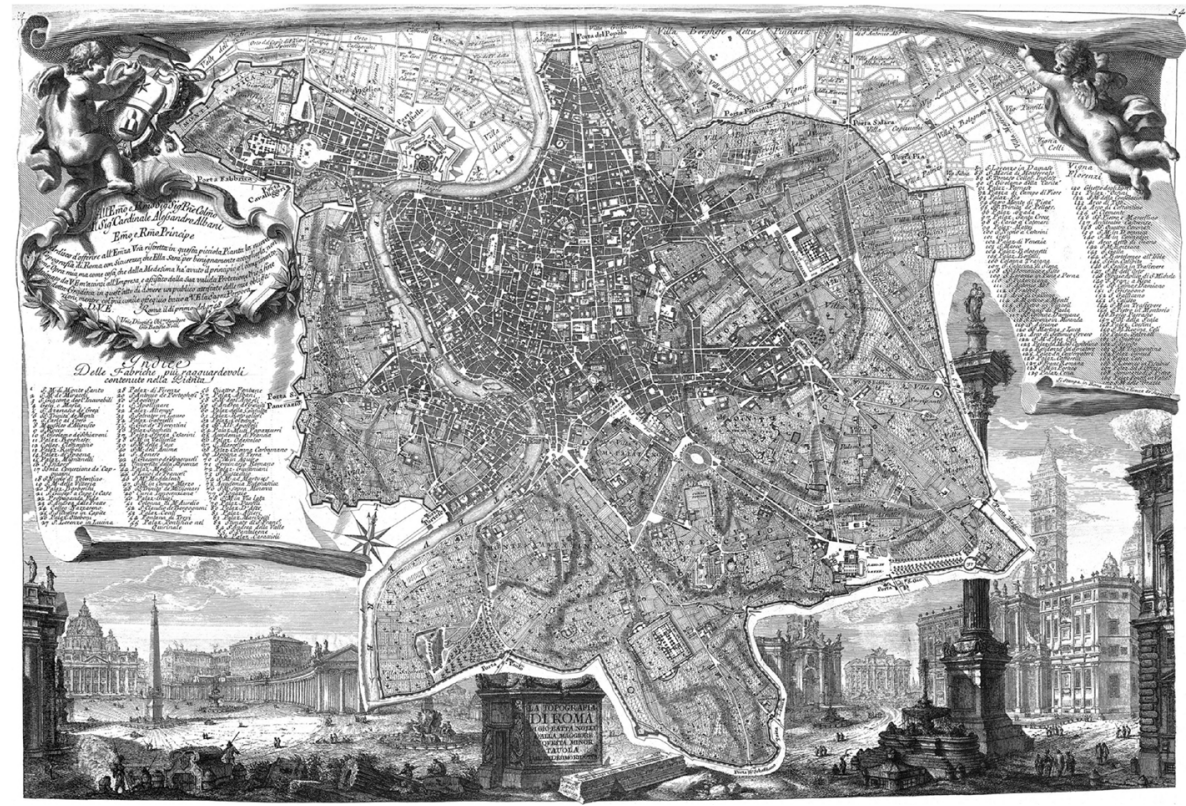

Figura 7. La topografia di Roma di Gio. Batta Nolli dalla maggiore in questa minor tavola dal medesimo ridotta (1748)

Giovanni Battista Piranesi, responsable además de las vistas urbanas y el resto de ornamentación que presenta la lámina. La segunda reducción, con un formato similar a la anterior $(457 \times 692 \mathrm{~mm})$ y dedicada al cardenal Silvio Valenti, constituye una reconstrucción topográfica de la «Roma antica», una reedición de la planta de Leonardo Bufalini (1551), y que, en cierto modo, sirvió como llamada a la consideración y conservación de los monumentos romanos. En el grabado participó, además de Carlo Nolli, Francesco Monaco, autor de la parte ornamental.

\section{Ejemplos de la Ilustración española: Madrid, Sevilla y Granada}

En la España del XVIII la renovación de la cartografía urbana ${ }^{25}$ constituye un aspecto esencial del gran empeño del reformismo borbónico ${ }^{26}$ por obtener una imagen fidedigna de su territorio y de sus ciudades. Los planos urbanos de la

25 Juan Calatrava, «Urban Mapping in Spain», en Edney y Pedley (eds.), Cartography in European Enlightenment, págs. 1604-1608.

26 Carlos SAmbricio, Territorio y ciudad en la España de la Ilustración, Madrid, Ministerio de Obras Públicas, 1991; Antonio T. Reguera, Territorio ordenado, territorio dominado, León, Universidad de León, 1995. 
España de las Luces eran, al mismo tiempo, un instrumento necesario de estas propuestas de reforma, que requerían de un conocimiento exacto y no aproximativo de la realidad de las urbes, y un objeto cultural en el que se plasmaban las ideas de progreso, felicidad pública y riqueza de la nación, así como, en no pocas ocasiones, la cara utópica del pensamiento ilustrado.

Este impulso cartográfico se produjo de la mano de la nueva intelligentsia de las Luces (científicos, ingenieros, geógrafos, geómetras...), con empresas que, en unos casos, fueron puro empeño personal (Tomás López, Francisco Dalmau...) y, en otros, producto colectivo de la cada vez más eficiente organización estatal y, sobre todo, de esa verdadera élite científica que fue el cuerpo de los ingenieros militares ${ }^{27}$, principales encargados de vehicular el esfuerzo de modernización de la nación e impulsores de una abundante producción cartográfica que, realizada según la más moderna metodología científica disponible, servía directamente a los intereses del aparato de Estado. Recordemos, por ejemplo, el papel que desempeñaron estos ingenieros en el momento en que la reestructuración de la marina promovida por el marqués de la Ensenada dio lugar a toda una cartografía específica - tanto territorial como urbana- de los focos centrales de tal renovación (en especial Cádiz y las poblaciones de su bahía, El Ferrol y Cartagena).

Del propio marqués de la Ensenada partió igualmente la iniciativa que habría de producir la más amplia recopilación de imágenes urbanas y territoriales de la España del xviII: el Catastro de Ensenada, un cúmulo de miles de descripciones escritas e imágenes de la Corona de Castilla realizadas entre 1749 y 1754. Aunque a menudo se trata de croquis sumarios y esquemáticos y no de documentos cartográficos sensu stricto, el conjunto de estos dibujos y los textos que los acompañan sigue siendo una fuente de conocimiento de primer orden aún lejos de ser explotada en su totalidad.

Debemos citar en primer lugar, por supuesto - aunque en este trabajo nos limitaremos a mencionarlo precisamente por ser la figura mejor conocida de nuestra cartografía ilustrada - a Tomás López ${ }^{28}$, quien, tras una larga etapa de formación en París, entre 1752 y 1760, emprendió una amplia obra cartográfica tanto territorial como urbana, con más de 200 mapas y planos en su haber, en

${ }_{27}$ Horacio Capel, Joan Eugeni SÁnchez y Omar Moncada, De Palas a Minerva: la formación científica y la estructura institucional de los ingenieros militares en el siglo XVIII, Barcelona, Serbal, 1988.

28 Agustín Hernando, «Panorama cartográfico de la España del siglo XVIII. Los mapas creados por Tomás López (1730-1802)», Mapping Interactivo. Revista Internacional de Ciencias de la Tierra, 116 (2007), págs. 14-20; Carmen Líter y Francisca SANChís, La obra de Tomás López. Imagen cartográfica del siglo XVIII, Madrid, Biblioteca Nacional de España, 2002; Antonio LóPez Gómez y Carmen Manso Porto, Cartografía del siglo XVIII. Tomás López en la Real Academia de la Historia, Madrid, Real Academia de la Historia, 2006. 
una labor en la que los aspectos científicos se vieron acompañados de una actitud de empresario particular en cuanto al comercio cartográfico que, aunque en Holanda e Inglaterra fuera habitual desde hacía largo tiempo, en España representaba una novedad absoluta.

De las dificultades de estas empresas cartográficas nos habla el ejemplo de la gran tentativa del propio Tomás López de elaborar un Diccionario Geográfico de España, un ambicioso proyecto que, por su propia envergadura, quedó incompleto e inédito y que se basaba en las respuestas a un cuestionario de quince preguntas enviado a cientos de ciudades y poblaciones españolas. Muchas de las respuestas recopiladas iban acompañadas de representaciones planimétricas de calidad muy desigual y que luego, con frecuencia, eran retocadas por el mismo López (al solicitar su envío, el cartógrafo aclaraba: «que aunque no esté hecho como de mano de un profesor, nos contentamos con solo una idea o borrón del terreno, porque la arreglaremos dándole la última mano»). El abismo entre las dimensiones de la empresa y la precariedad de los medios utilizados hace de este conjunto de imágenes — no obstante, valiosa fuente de información — todo un símbolo de las grandes dificultades con que tropezaba en España la difusión del pensamiento ilustrado.

La cartografía urbana de la Ilustración española fue, pues, un empeño en el que confluyeron, de manera desigual, disimétrica y a veces conflictiva, diferentes ramas de la Administración y particulares imbuidos del cientifismo ilustrado, constituyendo un sustrato del que surgió, en medio de todo un cúmulo de dificultades, una nueva generación de planos urbanos geométricos capaces de producir una imagen cada vez más exacta de la ciudad, con fines tanto representativos como pragmáticos, y susceptibles al mismo tiempo no solo de retratar la realidad, sino también de plasmar, en un horizonte de futuro, la aspiración ilustrada a una ciudad geométrica, clara y ordenada.

En Madrid, el punto de arranque de la moderna cartografía urbana fue la instrucción dictada en octubre de 1749 para la reforma de la Regalía de Aposento, vigente desde 1565 como consecuencia de la declaración de capitalidad de Madrid por Felipe II. En cumplimiento de esta instrucción, se llevó a cabo una Visita General de las casas de Madrid que implicó por primera vez la numeración de manzanas y casas. El reconocimiento de las manzanas se ejecutó entre 1750 y 1751 y el resultado fue, en 1762, la Relación General de todas las casas de Madrid, documento en base al cual se formó la Planimetría General de la ciudad (un conjunto cartográfico que ha sido considerado de carácter precatastral y que maneja seis escalas comprendidas entre, aproximadamente, 1:500 y 1:5600). Esta planimetría hizo posible, a continuación, el desarrollo de una 


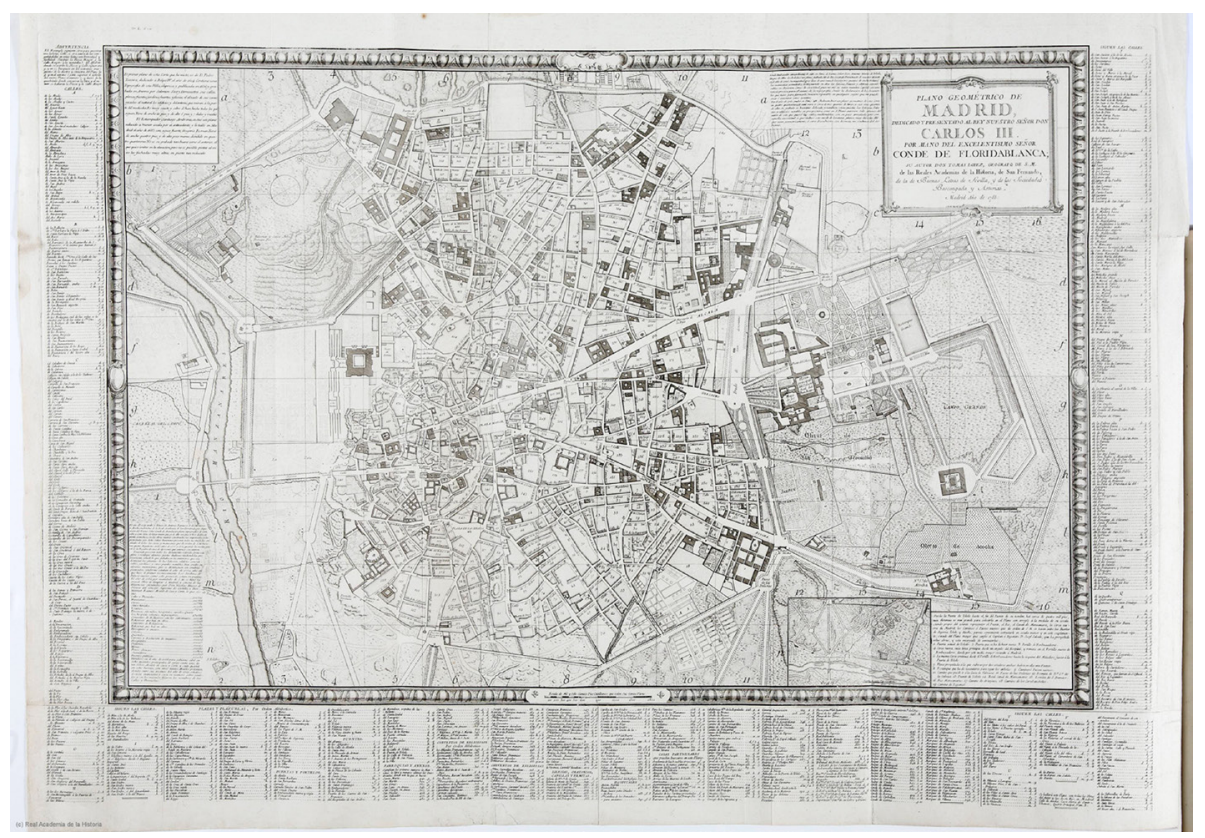

Figura 8. Plano geométrico de Madrid. Dedicado y presentado al Rey Nuestro Señor Don Carlos III. Por mano del Excelentísimo Señor Conde de Floridablanca, plano de Madrid de Tomás López a escala aproximada 1:5600 (1785)

cartografía urbana para una Villa y Corte ${ }^{29}$ que hasta la segunda mitad del xvIII contaba prácticamente solo con el plano realizado por Pedro Teixeira en 1656.

En este proceso, junto a los varios planos de Madrid de Tomás López, mucho más conocidos y estudiados, hay que citar de manera especial el realizado por Antonio Espinosa de los Monteros, el Plano topográphico de la Villa y Corte de Madrid (1769), también conocido como plano del Conde de Aranda, de quien partió el encargo y a quien está dedicado. El plano de Espinosa, que utilizó los levantamientos de la mencionada Visita General, es un documento cartográfico de 9 hojas, a una escala aproximada de 1:1900 y con abundante texto explicativo. En él aparecen por primera vez las 557 manzanas madrileñas numeradas. Y, precisamente, la núm. 1 correspondía al nuevo Hospital de Atocha, el pro-

29 Miguel Molina Campuzano, Planos de Madrid de los siglos XVII y XVIII, Madrid, Ministerio de Administraciones Públicas, 2002; Carlos Sambricio y Concepción Lopezosa Aparicio, Cartografía histórica. Madrid. Región Capital, Madrid, Comunidad Autónoma de Madrid, 2002; Joaquín Álvarez Barrientos, Cultura y ciudad. Madrid, del incendio a la maqueta (1701-1833), Madrid, Abada Editores, 2017. El Plano geométrico de Madrid. Dedicado y presentado al Rey... (Madrid, 1785), elaborado por Tomás López, es accesible online en http://bibliotecadigital.rah.es/es/consulta/registro.do?id=12648. 


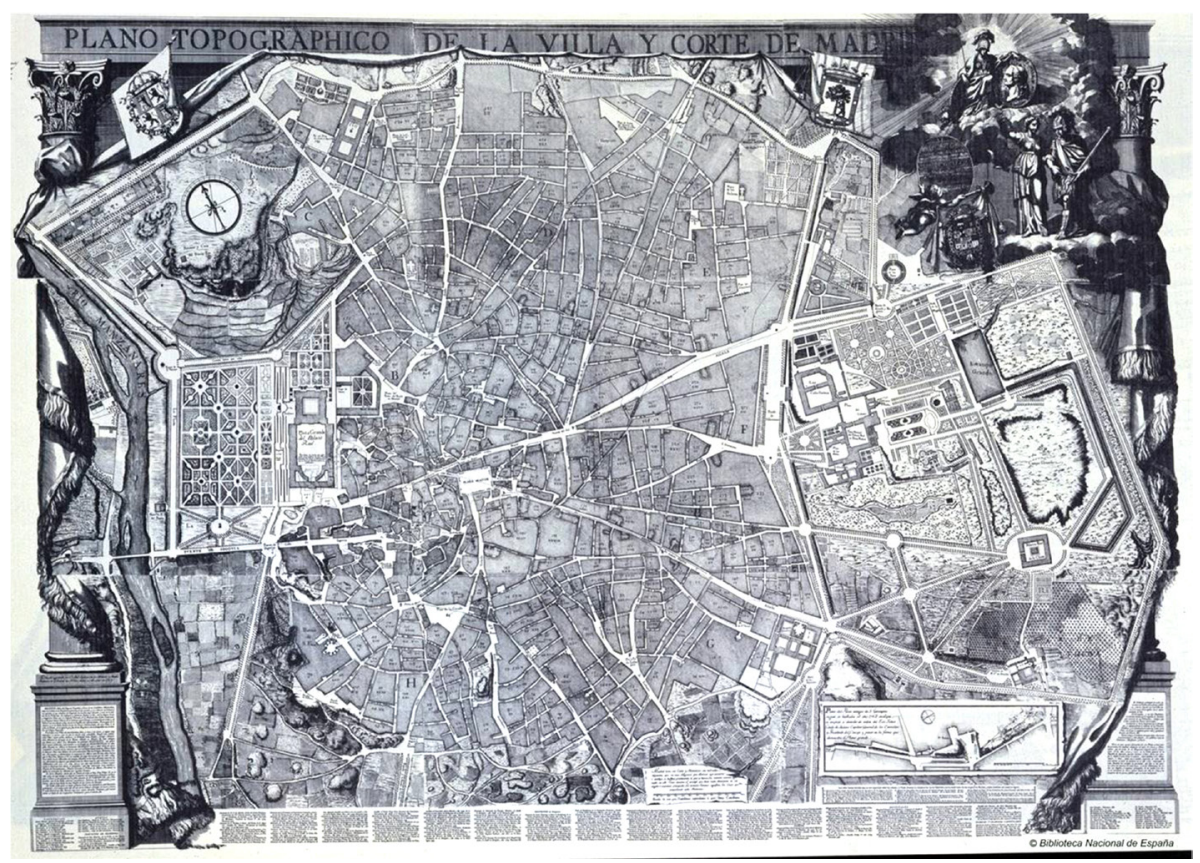

Figura 9. Plano topográphico de la Villa y Corte de Madrid o plano del Conde de Aranda (1769)

yecto inicialmente de Hermosilla y después de Sabatini que estaba llamado a cerrar por su ángulo suroeste el gran diseño del Paseo del Prado como nuevo eje del Madrid de las Luces, contrapuesto al viejo Madrid de los conventos e iglesias. Lo significativo es que el gran hospital se representaba en el plano como si la totalidad del proyecto, con sus cinco patios, hubiese sido efectivamente construida, situación que, como bien sabemos, no se dio. Igual ocurrió con el proyecto de ampliación del Palacio Real ideado por Sabatini. El plano de Espinosa de los Monteros refleja, así, la tensión — que recorre en realidad toda la cultura de las Luces - entre la exactitud científica y el futuro anhelado pero aún no (y con frecuencia nunca) presente, es decir, esa dimensión utópica que en 1963 Pierre Francastel consideró como un componente básico de las Lumières e inescindible de su pragmatismo ${ }^{30}$.

Lo cierto es que, pese a todos los problemas inherentes a la propia debilidad de nuestra Ilustración, diversas ciudades españolas lograron, en la segunda mitad del siglo XVIII, dotarse por vez primera en su historia de planos

30 Pierre Francastel (ed.), Utopie et institutions au XVII siècle. Le pragmatisme des Lumières, París / La Haya, Mouton, 1963. 
modernos realizados a partir de los principios y los métodos de la nueva cartografía científica.

Además de los de Madrid de López y Espinosa de los Monteros, otro de los ejemplares más destacados de esta cartografía es el Plano Topográphico de la M[uy] N[oble] Y M[uy] L[eal] ciudad de Sevilla (1771), conocido habitualmente como plano de Olavide, por tratarse de un encargo del célebre asistente de la ciudad $^{31}$. Es bien sabido cómo Pablo de Olavide, a partir de 1767, ya como asistente de Sevilla, impulsó importantes reformas que tenían que ver con la mejora de infraestructuras (evacuación de aguas residuales, fuentes de agua potable, estacadas de contención en las márgenes del río), la ampliación de puertas, la apertura de avenidas, el adoquinado de plazas y calles e, incluso, la creación de todo un barrio, la Laguna (con un trazado ortogonal y simétrico) ${ }^{32}$.

Este fue el clima reformista en el cual se concibió y elaboró el plano hispalense. Pero, dicho esto, también conviene señalar que la utilidad real del documento en cuanto herramienta práctica catastral o de planificación urbanística resulta dudosa y cuestionable. No es posible obviar, por ejemplo, la desatención del plano a la reorganización administrativa introducida en Sevilla y otras capitales españolas por la Real Cédula de 13 de agosto de $1769^{33}$. A diferencia del plano de Espinosa de los Monteros, la planimetría de Olavide ni alude directamente a la nueva estructura administrativa de la ciudad ni presenta indicios al respecto, aunque la emisión de la mencionada cédula y la elaboración del plano fueran prácticamente contemporáneas ${ }^{34}$.

31 Una cartela rectangular situada en el ángulo inferior derecho del plano informa: «Se levantó, y abrió por disposición del S. ${ }^{\text {or }}$ D. ${ }^{\mathrm{n}}$ Pablo de Olavide, asistente de esta ciudad, intendente del exercito, y provincia de Andalucia, y superintendente de las nuevas poblaciones de Sierra Morena, y Andalucia. Año de 1771».

32 Francisco Aguilar Piñal, La Sevilla de Olavide, Sevilla, Ayuntamiento de Sevilla / ICAS, 2015; Marcelin Defourneaux, Pablo de Olavide ou l'Afrancesado (1725-1803), París, Presses Universitaires de France, 1959; Juan Marchena Fernández, El tiempo ilustrado de Pablo de Olavide: vida, obra y sueños de un americano en la España del s. XVIII, Sevilla, Alfar, 2001; Luis Perdices de Blas, Pablo de Olavide (1725-1803), el ilustrado, Madrid, Editorial Complutense, 1993.

33 Real Cédula de S.M. y señores del Consejo, de 13 de agosto de 1769, con la instrucción de lo que deben observar los Alcaldes de barrio, y demas que contiene. Este documento estableció la división de Sevilla en 5 cuarteles — «uno del arrabal de Triana, y los cuatro se formen del casco de la Ciudad» (pág. 4)—, subdivididos a su vez en 8 barrios. A continuación, la Real Cédula establecía: «Todas las casas de las referidas Ciudades, inclusas parroquias, conventos, iglesias y lugares pios se numerarán con azulejos, como tambien las casas de Ayuntamiento y las de las Chancillerías y Audiencias, sin exceptuar alguna por privilegiada que sea, distinguiéndolas en Manzanas, como se ha hecho en Madrid, y á costa de sus dueños» (pág. 6).

34 Aunque es posible que los trabajos de medición y levantamiento hubieran terminado meses antes de la emisión de la cédula, a finales de 1768 (según se apunta en Ignacio Algarín VéLEz, Método de transcripción y restitución planimétrica: su aplicación al estudio del plano de Sevilla de 1771 mandado levantar por disposición del Sr. D. Pablo de Olavide, asistente de esta ciudad, Sevilla, Secretariado de Publicaciones de la Universidad de Sevilla, 2000, pág. 39), transcurrieron tres años hasta su edición definitiva en 1771 y, por 
Probablemente, el Plano Topográphico de la M.N Y M.L. Ciudad de Sevilla tenía como finalidad principal el servir no tanto como utensilio de planeamiento urbanístico cuanto como dispositivo de conocimiento y gobierno. En una carta del 23 de septiembre de 1771 al conde de Aranda, Olavide escribió: «Hasta ahora no se había sacado Plano alguno de una ciudad tan vasta y numerosa como esta de Sevilla, y siendo difícil comprenderla, era mucho más difícil gobernarla ${ }^{35}$. Parece claro, por tanto, que el plano sevillano se gestó para proporcionar una imagen inteligible, global y precisa que facilitara el control de la ciudad. A ello hay que añadir una motivación ancestral y no menos importante: la posesión de un documento cartográfico como metáfora del poder. Así lo apoya el hecho de que Olavide enviara una copia de la obra a los principales miembros de la realeza, varios abates, así como diversos nobles y ministros del Gobierno ${ }^{36}$.

Con independencia de su finalidad, se trató de un documento innovador. De una parte, parece que fue el primero - al menos entre los planos conocidosen ofrecer una imagen general de la Sevilla amurallada (algo llamativo, pues es una fecha muy tardía para una urbe de semejante magnitud e importancia estratégica). De otra parte, fue, además, el primer levantamiento topográfico de la ciudad, realizado con métodos y artefactos científicos (teodolito, grafómetro, plancheta, alidada, etc.). No es de extrañar, por tanto, que recibiera el reconocimiento de la Academia de San Fernando ${ }^{37}$. La confección del trabajo se debe a Francisco Manuel Coelho, delineante de la intendencia y amigo y colaborador de Olavide en la planificación de las Nuevas Poblaciones de Andalucía, y a José Amat, maestro grabador que realizó la talla dulce sobre planchas de cobre ${ }^{38}$.

Según un ejemplar perteneciente a la primera tirada y conservado en la Real Academia de la Historia ${ }^{39}, 935 \times 1370 \mathrm{~mm}$ y 1:2650 son, respectivamente, las dimensiones y la escala aproximada del grabado original. Presenta una escala gráfica de 600 varas castellanas $(=188 \mathrm{~mm})$ y una rosa de los vien-

tanto, habría sido factible — más aún teniendo en cuenta la dinámica de elaboración de las obras cartográficas- la inclusión de nuevas referencias acordes con la orden.

35 Archivo de Simancas. Sección Inquisición. Reproducida en Algarín VÉLEz, Método de transcripción y restitución planimétrica, págs. 39-40.

36 La mencionada carta al conde de Aranda incluye una relación de los planos a entregar: «Uno para el Rey. Uno para el Príncipe. Dos para Aranda. Dos para Grimaldi. Uno para Murquiz y otro para Campomanes. Uno para el abate Samaniego, Roda, Arriaga, Losada».

37 Según se indica al final del texto que recoge la cartela rectangular: «Premiado por la R. ${ }^{1}$ Academia de S. ${ }^{n}$ Fernando».

38 Estos datos de autoría figuran igualmente en la cartera rectangular: «Lo Levantó y delineó D. ${ }^{\mathrm{n}} \mathrm{F}^{\mathrm{co}}$ Man. ${ }^{1}$ Coelho, y lo Gravó D. ${ }^{\mathrm{J}}$ Jph Amat».

39 Francisco Manuel Coelho (delineante) y José Аmat (grabador), Plano Topográphico de la M[uy] N[oble] Y M[uy] L[eal] ciudad de Sevilla, s. 1., 1771. Accesible online: http://bibliotecadigital.rah.es/es/consulta/registro.do?id=12767, consultado el 1 de octubre de 2019. 
tos de ocho puntas con el norte en flor de lis girado unos $73^{\circ}$ en sentido antihorario (con cierta desviación respecto al norte real). En el extremo opuesto de la cartela rectangular — rematada con el escudo de armas de Olavide-, el título del plano queda recogido en una cartela barroca decorada con ramas de olivo y coronada por el emblemático jeroglífico sevillano «NO \& DO». En la parte superior, centrada, una filacteria con la inscripción «Sevilla» corona el dibujo.

En los márgenes izquierdo y derecho, bajo el título «Explicacion de este mapa», se despliega una relación de 211 localizaciones (identificadas por un número) entre las que se encuentran puertas, parroquias, conventos, etc., además de una categoría denominada «Edificios y cosas particulares», dentro de la cual figuran, por ejemplo, el alcázar, la catedral o la lonja ${ }^{40}$. Sobre el dibujo, prácticamente todos los edificios reseñados en la leyenda se representaron con detalle y en seudoperspectiva, por el abatimiento de sus fachadas principales de modo tal que los espacios públicos no resultaran invadidos; asoman, aquí, anteriores criterios de representación gráfica.

El resto de la trama urbana es muy sencilla: manzanas dibujadas mediante polígonos cerrados y sombreados a base de puntos y trazos cortos que, aplicados casi sistemáticamente en los linderos sur y oeste, aportan sensación de volumen. Sobre esta trama aparecen los nombres de la mayoría de las calles y plazas.

Las barriadas extramuros se representaron de manera más somera. Es el caso de la Macarena, poco visible en el lateral izquierdo, y de Triana, prácticamente oculta por la cartela rectangular, aunque sea posible reconocer el puente, el castillo de la Inquisición y el convento de los Remedios.

Más allá de las murallas se trazaron con detalle, por ejemplo, la Plaza de Toros, la Real Fábrica de Tabaco — cuya construcción finalizó en el mismo año en que se editó el plano (1771)—, el Palacio de San Telmo o el Hospital de la Caridad. No sucedió así, en cambio, con el Hospital de las Cinco Llagas, del cual no hay rastro en el plano no obstante su importancia y pese a que otros edificios menos destacados, como el matadero o el quemadero de herejes, aparezcan reseñados en la leyenda y dibujados en planta.

El escaso espacio extramuros representado — pues el encuadre se ajustó bastante a los límites de la villa— queda cubierto principalmente por el Guadalquivir, el terreno agrícola (simulado mediante una convencional combinación de tramas) y el arbolado (en perspectiva). En la zona superior de la imagen

40 Las doce categorías que componen la leyenda son: «puertas», «parroquias», «ayudas de parroquias», «comunidades», «conventos de monjas», «beateríos», «hermitas donde se celebra», «colegios y seminarios», «hospitales de curación», «hospitales de casas de misericordia», «edificios y cosas particulares» y «plazas y calles que por su pequeñez no se pudieron nominar en el Plano». 


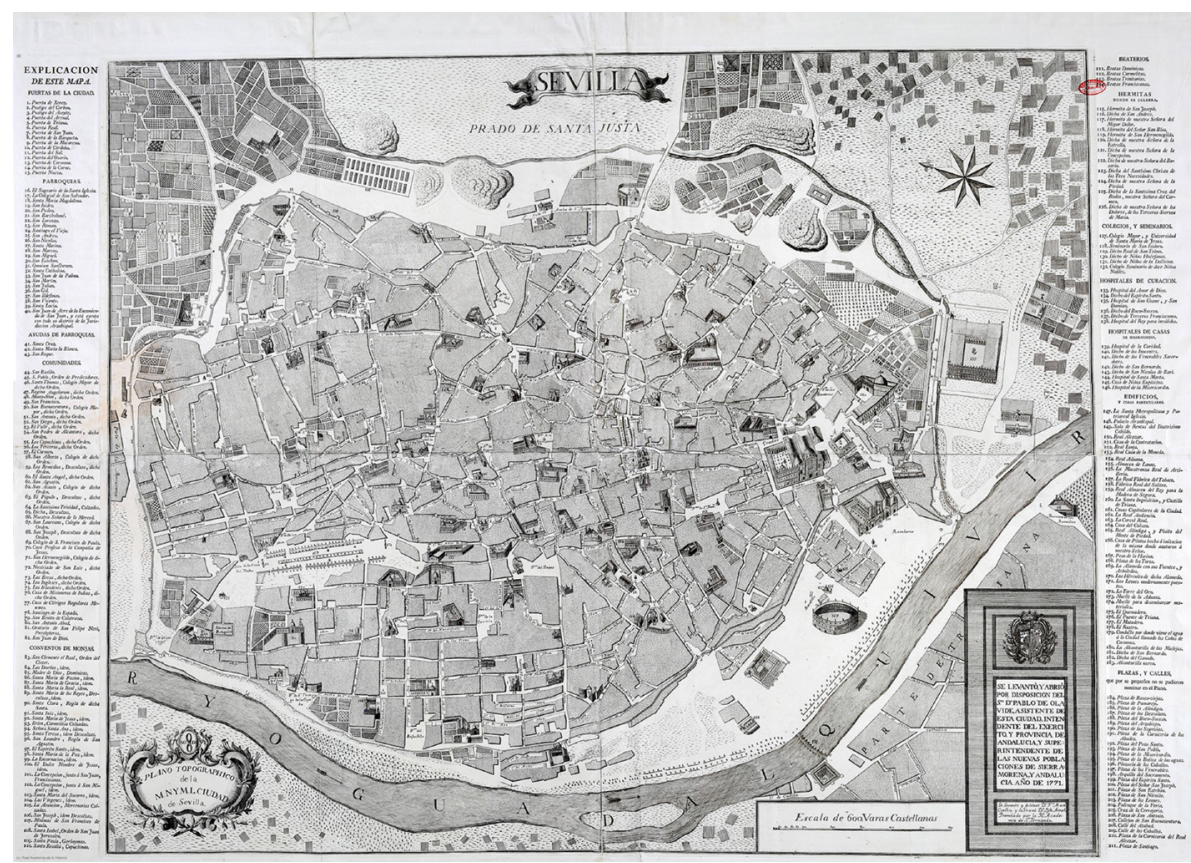

Figura 10. Plano Topográphico de la M.N Y M.L. Ciudad de Sevilla o plano de Olvide (1771)

destacan el arroyo Tagarete y la representación, con primitivas curvas de nivel, de las principales elevaciones del terreno. El potente grafismo del Guadalquivir, a base de líneas onduladas paralelas a las que se superpone un rótulo, es merecedor de atención. Su posición en la base de la composición, gracias a la orientación escogida para el plano, le aporta un protagonismo que estaba en sintonía con su papel en la economía sevillana, pues el río era la vía para las mercancías más pesadas y todo lo procedente de América ${ }^{41}$.

Usando como base el plano de Olavide, casi dos décadas después Tomás López levantó su Plano geométrico de la ciudad de Sevilla (1788), lo que hizo que la capital andaluza contara en un breve intervalo con dos importantes muestras de la cartografía urbana ilustrada. Dedicada al asistente Pedro López de Lerena, esta representación incorporó las adiciones del nuevo barrio de Triana y las obras realizadas tras la devastadora riada de 1783, según se indica en la

${ }_{41}$ Francisco Agullar Piñal, Historia de Sevilla. Siglo XVIII, Sevilla, Editorial Universidad de Sevilla, 1989; José Beltrán Fortes y Luis Méndez Rodríguez (coords.), Sevilla en el Siglo de la Ilustración, Sevilla, Editorial Universidad de Sevilla, 2018; Comisaría de la Ciudad de Sevilla Para 1992 (ed.), La Sevilla de las Luces, Sevilla, Ayuntamiento de Sevilla, 1991. 
nota inserta en el ángulo inferior izquierdo ${ }^{42}$. Como gran novedad cartográfica, el plano de López incorporó a la explicación del plano de Olavide un índice alfabético de calles y un sistema de localización alfanumérico en correspondencia con la división en cuadrículas de la trama urbana dibujada.

Llegamos así a nuestro último caso de estudio, el Mapa topográfico de la ciudad de Granada, según la situación y forma que tenía en el año de 1796 (1796), ideado y realizado por el matemático de origen catalán Francisco Dal$\mathrm{mau}^{43}$.

El Cabildo granadino se había contentado durante casi dos siglos con la representación urbana delineada por Ambrosio de Vico, maestro mayor de la catedral, y conocida como Plataforma de Vico. Concebida para formar parte de la inédita Historia eclesiástica de Granada del clérigo Justino Antolínez de Burgos, es una perspectiva caballera deliberadamente distorsionada que servía a propósitos más de orden religioso, político y simbólico que científico ${ }^{44}$. No modificaron esta situación algunas tentativas cartográficas esporádicas que se sucedieron a lo largo del siglo XVIII. Sirva como ejemplo el rudimentario plano, carente de rigor geométrico aunque con clara vocación científica, realizado por el médico Francisco Fernández Navarrete para su Cielo y suelo granadino

${ }^{42}$ Respecto a las obras nuevas, la nota cita: « $1^{\text {a }}$ Un Malecón desde la muralla del Blanquillo hasta el hospital de la Sangre, hecho con tierra y calibres, que no se manifiesta en este plano por no alcanzar la comprehensión de su escala. $2^{\text {a }}$ Reedificación de la muralla, que estaba arruinada, desde la puerta de San Juan, hasta la de Colón. $3^{\text {a }}$ Alamedas y Malecones de piedra señalados con la letra A, desde el almacén del Rey hasta la torre de Lorito, con asientos en toda su extensión, y cinco entradas o salidas para el paso del público, anotadas con B, executadas de piedra de sal y pez, con sus alefrices y tablones, para en tiempo de avenidas del río. $4^{\text {a }}$. El puente nuevo $\mathrm{C}$, que da paso al barrio de Triana, el que se halla con prevenciones dobles, para su resguardo, que antes no tenía. $5^{\mathrm{a}}$. El primoroso puente $\mathrm{D}$, llamado el Tagarete, que da paso al sitio de la torre del Loro». El Plano geométrico de la ciudad de Sevilla. Dedicado al Excelentísimo Señor Don Pedro López de Lerena... (Madrid, 1788), elaborado por Tomás López, es accesible online en http://bibliotecadigital.rah.es/ es/consulta/registro.do?id=12668.

43 La figura de Francisco Dalmau ha sido estudiada en profundidad por Julio Juste Ocaña, Útil y sutil: Francisco Dalmau y el Plano topográfico de Granada de 1796 (Trabajo de investigación inédito), Granada, Universidad de Granada, 2005. Sobre su «mapa topográfico», véase: Juan Calatrava y Mario Ruiz Morales, Los planos de Granada, 1500-1909. Cartografía urbana e imagen de la ciudad, Granada, Diputación Provincial de Granada, 2005, págs. 71-82; Ana del Cid Mendoza, «La Granada que pudo ser. Mapas y planos como herramienta de planificación urbanística (I)», Cartografía urbana e historia de la ciudad. Granada y Nueva York como casos de estudio (Tesis doctoral inédita), Universidad de Granada, 2015, págs. 149-166. En 1819 Dalmau realizó un segundo plano de Granada, que trasciende la escala urbana para mostrar las relaciones de la urbe con el espacio agrícola circundante, estudiado por Luis J. GARCía PuLIDO, «Una precisa y artística representación gráfica del territorio granadino: el Mapa topográfico de la ciudad de Granada y su término de Francisco Dalmau (1819)», Cuadernos de Arte de la Universidad de Granada, 44 (2013), págs. 171-198.

44 Juan Manuel Barrios Rozúa, «La Plataforma de Granada de Ambrosio de Vico», en Francisco Javier Martínez Medina (coord.), Jesucristo y el Emperador Cristiano, Córdoba, CajaSur, 2000, págs. 133-136; Calatrava y Ruiz Morales, Los planos de Granada, págs. 101-110; del Cid Mendoza, «Un "plano" que no lo es: la plataforma de Ambrosio de Vico», Cartografía urbana e historia de la ciudad, págs. 129-145. 
(1732) — una novedosa descripción de la ciudad que no llegó a editarse ${ }^{45}$ — o el caso de la esquemática representación a escala de la Vega de Granada realizada por el clérigo Luis de Vargas Carrillo y enviada desde Santa Fe al omnipresente Tomás López para formar parte del Diccionario Geográfico de España ${ }^{46}$.

Solo a finales de siglo, gracias a la tenacidad de un erudito foráneo, tomó cuerpo la idea de elaborar un plano científico acorde a la realidad urbana y la técnica cartográfica del momento. Francisco Dalmau pertenecía a la activa minoría ilustrada preocupada por fomentar la difusión social de la ciencia y la cultura. En Granada, donde residió desde 1790 hasta su muerte en 1824, mantuvo una incesante actividad docente y cultural: maestro de matemáticas (como se define en su plano $)^{47}$, director de Arquitectura de la Escuela de Dibujo de Granada, y creador, editor —y, prácticamente, autor en solitario — del semanario Mensajero Erudito y Económico de Granada ${ }^{48}$. Cabe destacar aquí el artículo «Retrato natural de Granada», editado por entregas en el Mensajero en junio de 1796 y que constituyó parte del sustrato teórico del plano topográfico granadino, el cual vio la luz en diciembre del mismo año.

A diferencia del plano de Olavide, el de Dalmau no procede de una iniciativa institucional, sino que es resultado del empeño individual de su autor. El 6 de junio de 1795, Dalmau planteó al consistorio granadino la necesidad de realizar un verdadero plano científico, mediante un escrito ${ }^{49}$ que resume los objetivos ideológicos de la iniciativa: si, por un lado, esgrime la tradicional idea encomiástica de la difusión de la «hermosura y feliz situación» de la ciudad, por otro se acoge al principio ilustrado de la utilidad pública. En este último sentido, la funcionalidad principal del plano sería la de fijar en una imagen el recuerdo histórico de la ciudad. En palabras del propio Dalmau: «Las ciudades nacen, se forman y perecen [...] Los mapas topográficos son los epitafios de las ciudades». El matemático reivindicaba así el valor del plano científico como testimonio fehaciente de la historia, a diferencia de las «crónicas» barrocas envueltas en mitificaciones.

En la misma instancia Dalmau declaraba su admiración por el Plano Geométrico de Madrid (1785) de Tomás López, que se convertiría en un modelo

\footnotetext{
45 Francisco Fernández Navarrete, Cielo y suelo granadino, ed. del manuscrito inédito a cargo de Antonio Gil Albarracín, Almería / Barcelona, Ediciones GBG, 1997.

46 Tomás López, Diccionario Geográfico de Andalucía: Granada, ed. a cargo de Cristina Segura y Juan Carlos de Miguel, Granada, Don Quijote, 1990.

47 En la cartela reza: «Maestro de Matemáticas del Rl. Cuerpo de Maestranza de Caballería de esta Ciudad y Académico de la Rl. Academia de Ciencias naturales y Artes de Barcelona».

48 La colección completa, compuesta por 139 fascículos publicados entre el 2 de junio de 1796 y el 28 de septiembre de 1797, se encuentra en la Hemeroteca de la Casa de los Tiros (Granada).

49 Archivo Municipal de Granada: legajo 1876, pieza 17. Reproducido en Calatrava y Ruiz Morales, Los planos de Granada, págs. 144-145.
} 


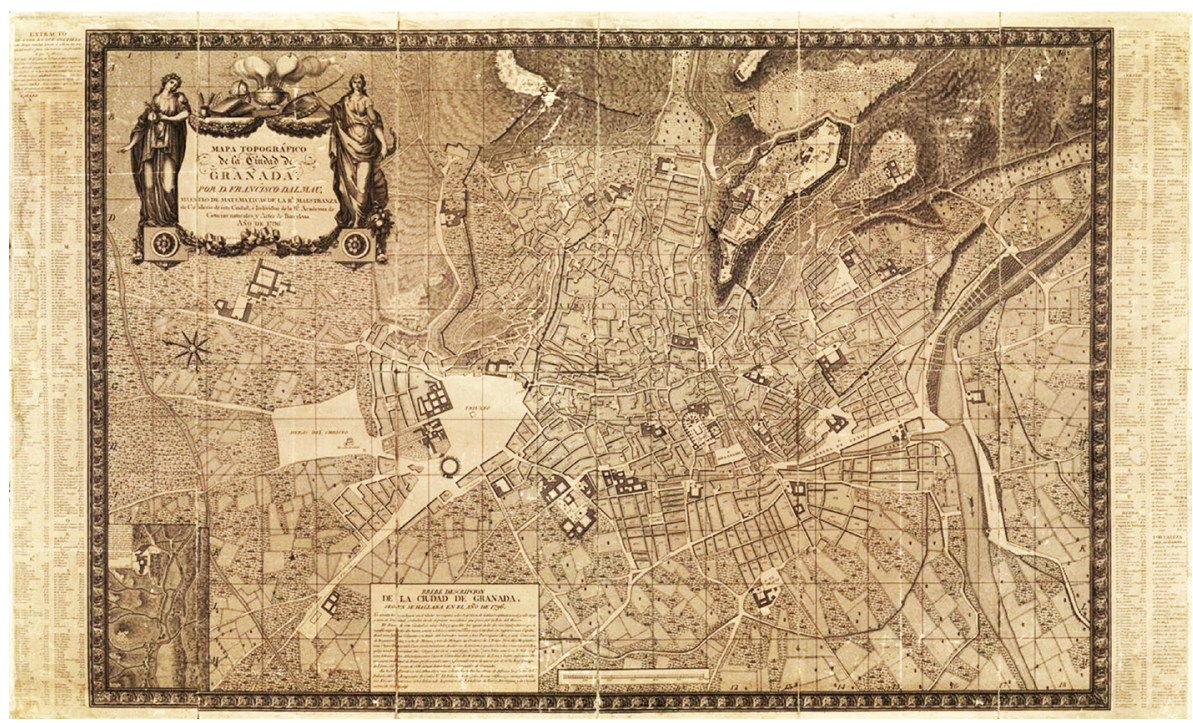

Figura 11. Primera versión grabada del Mapa topográfico de la ciudad de Granada de Francisco Dalmau (1796)

a seguir, así como su intención de llevar a cabo un amplio y riguroso trabajo de campo. El Cabildo aceptó su propuesta, no sin la presión ejercida por influyentes miembros de la élite granadina ${ }^{50}$. El resultado final fue un plano - hoy conservado en el Archivo Municipal de Granada ${ }^{51}$ — de grandes dimensiones $(2360 \times 3400 \mathrm{~mm})$, a una escala aproximada de 1:2900, y que fue entelado y exhibido en la Casa Consistorial como imagen de la ciudad que los regidores estaban llamados a transformar en aras del progreso.

Precisamente fue el doble criterio de la difusión y la utilidad lo que determinó que, desde el inicio, se planteara la realización de una versión grabada más pequeña, manejable y asequible, de $630 \times 1020 \mathrm{~mm}$ y escala aproximada 1:4000, que se ofreció a la venta por suscripción ${ }^{52}$. En 1831 se editó, incluso, una segunda versión (con similares dimensiones y escala) en la que se inclu-

50 Hay constancia de que uno de los grandes defensores de la empresa fue Pedro Mora, capitán de fragata, matemático de la Real Maestranza de Caballería y, en aquel entonces, Procurador Síndico Personero del Común.

51 Francisco Dalmau, Mapa topográfico de la ciudad de Granada, Granada, 1796. Accesible online: https:// www.granada.org/inet/wcartografia.nsf/xtod/8EEAA834F1C6B43BC12573F0002F9A6F?open, consultado el 1 de octubre de 2019.

52 Francisco Dalmau (delineante) y Francisco Ribera (grabador), Mapa topográfico de la ciudad de Granada, s. 1., 1796. Accesible online: https://www.granada.org/inet/wcartografia.nsf/xtod/B8B8A4DDC35D6 9CCC125760A0036A6DF?open, consultado el 1 de octubre de 2019. 
yeron las reformas acometidas en la ciudad durante el periodo transcurrido ${ }^{53}$. Este hecho constituye, sin duda, una prueba indirecta del alto nivel científico alcanzado por Dalmau con su trabajo.

El primer rasgo que otorga al plano su trascendencia es la incorporación de una cuadrícula de 12 filas (designadas con letras de la $A$ a la $M$ ) y 18 columnas (con números arábigos), a semejanza de las incluidas por Tomás López en sus planos geométricos de Madrid (1785) y Sevilla (1788). La cuadrícula es el soporte sobre el cual se articula el segundo aspecto innovador del plano: una detallada y muy extensa leyenda en la que cada referencia tiene una localización alfanumérica que la ubica con exactitud dentro de un cuadrante. La leyenda, desplegada en el borde inferior del plano original (lamentablemente muy deteriorado en esta zona) y en los márgenes laterales de la versión grabada ${ }^{54}$, incluye - además de una relación de edificios significativos - un listado por orden alfabético de todas las calles. El plano de Dalmau constituye, por tanto, el primer callejero de la historia de Granada. Como tercer rasgo de modernidad debemos señalar, por último, la numeración de las manzanas, una herramienta al servicio de la organización catastral. Todo este sistema (la representación en sí y la profusa información e indicaciones) es, una vez más, el reflejo en clave cartográfica de ese anhelo ilustrado del control absoluto y sin fisuras de la realidad.

El carácter avanzado del plano de Dalmau fue, por lo demás, puesto de relieve en 1805 por el afrancesado Simón de Argote en sus Nuevos paseos históricos, artísticos, económico-políticos, por Granada y sus contornos, donde lo señalaba explícitamente como base de su trabajo, contraponiendo su rigor a ese «mal paño de pintura» que, en su opinión, era la Plataforma de Vico ${ }^{55}$. La obra de Dalmau constituía, así, por primera vez en la historia de la ciudad, el retrato fidedigno de una Granada que en breve iba a sufrir los procesos modernizadores del XIX. De hecho, se convirtió en soporte visual para las primeras propuestas de transformación hasta que en 1853 se editó un nuevo plano (el de Rafael Contreras) en cumplimiento de la R.O de 1846 sobre planos geométricos de poblaciones.

53 En la cartela que figura en el margen inferior del grabado se hace mención explícita a esta tarea de actualización: «El presente Mapa se halla arreglado al estado de Granada en 1831 y para ello se han hecho las innovaciones siguientes...». Francisco DaLmau (delineante) y Francisco Ribera (grabador), Mapa topográfico de la ciudad de Granada, s. 1., 1831. Accesible online: https://www.granada.org/inet/wcartografia.nsf/xtod/83 2F6AEFE9290D81C12573F00030B3D2?open, consultado el 1 de octubre de 2019.

54 La transcripción de toda la leyenda (y el resto de los textos incluidos en el plano) en DEL Cid MENDOZA, Cartografía urbana e historia de la ciudad, págs. 537-552.

55 Simón de ARgote, Nuevos paseos históricos, artístico, económico-políticos, por Granada y sus contornos, Granada, 1805, vol. I, pág. 8. Véase, además, Juan Calatrava, «Un retrato de Granada a principios del siglo xix: los Nuevos paseos de Simón de Argote», Demófilo, 35 (2000), págs. 95-110. 


\section{Conclusiones}

La cartografía del siglo de las Luces constituye un laboratorio privilegiado para comprender hasta qué punto los mapas, los planos y, en general, las representaciones del mundo constituyen constructos histórico-culturales de enorme riqueza para la historiografía si se sabe interrogarlos adecuadamente. Desterrada ya la idea de que el interés de un plano habría de medirse únicamente por su mayor o menor grado de exactitud, la revisión de algunos de los ejemplares más paradigmáticos de la cartografía urbana del siglo XVIII confirma los argumentos ya planteados en la introducción de este trabajo, que se encuadra asimismo en el amplio movimiento de reforma de los estudios cartográficos de las últimas décadas.

A partir de los casos de estudio de París, Roma, Madrid, Granada o Sevilla queda claro, como no podía ser de otro modo, que los mapas y planos de las Luces son expresión polisémica de su época. Constituyen, por ello, un campo del saber en el que se despliegan avances del conocimiento científico, mejoras técnicas, nuevos conceptos filosóficos y políticos (tales como progreso, felicidad pública y riqueza de la nación), pero también renovadas formas de control, tensiones políticas y dificultades de todo tipo...

Así, la concurrencia del criticismo ilustrado con los progresos científicos y geográficos, pero también con las nuevas exigencias de unos Estados en pleno proceso de reforma modernizadora, constituyó tanto el motor como el contexto de una auténtica explosión cartográfica, no solo a nivel cuantitativo, sino también por lo que se refiere a la diversidad de tipos, de objetivos y de usos de los documentos cartográficos. Sobre los mapas y planos, toda esta renovación de las Luces se puede resumir en los tres verbos que encabezan el presente trabajo: medir, controlar y proyectar. Es decir, medir (y representar) alude a la necesidad de producir una imagen científica fiable del entorno del ser humano, pero apunta, igualmente, tanto a la exigencia de controlar, desde ese paradójico maridaje que se establece entre el deseo ilustrado de libertad frente al despotismo y el paralelo surgimiento de nuevas formas modernas de autoridad, como a la acción de proyectar. Esta última, más novedosa quizás, se debe entender, asimismo, no solo en el sentido de fijar o perpetuar una imagen, sino en el de trazar planes y reformas sobre la trama urbana, como una visión de futuro que hará en adelante de los planos de ciudad no ya meros retratos de la realidad, sino imprescindibles herramientas para la transformación de dicha realidad. 